\title{
Material properties and the energy balance in standardized fire testing
}

\author{
Wojciech Węgrzyński ${ }^{1, *}$, and Piotr Turkowski ${ }^{1}$ \\ ${ }^{1}$ Building Research Institute, Filtrowa St. 1, Warszawa 00-611, Poland
}

\begin{abstract}
The origins of standardised fire testing can be traced back to 1870 's, and the origin of the standard temperature-time curve to 1917. This approach, based on a 19th-century intuition is still in use up to this day, to design the 21 st-century structures. Standardized fire-testing ultimately disregards the conservation of energy in the fire, as in every test the resulting temperature of the test must be the same (precisely as the temp.-time curve). To maintain this, different amount of heat is required in every test, which means that every time a different fire is modelled within the furnace. The differences between furnace fire sizes are ignored in the certification process, but can be interesting for fire researchers to understand how different materials behave in fire conditions. In this paper, Authors explore this topic by investigating the energy balance within the furnace, and comparing different fire tests together.
\end{abstract}

\section{Introduction}

The fire testing was a strong force shaping the civil engineering development [1], accelerating the transition from wood and stone based structures into the modern world of concrete, steel and glass. The dissemination of fire-proof solutions with code-based prescriptive requirements resulted in observable change in the damage caused by fires to the buildings. As this approach was successful in limiting the costs of fires, it was not significantly changed since the first fire tests of XIX-th Century, and the standardised fire resistance tests are still the ultimate rating for fire performance of structures.

The main problem with the idea of temperature-time index evaluation of construction products is the lack of inclusion of a feedback loop between the fire and the structure. In the standard fire resistance test, the temperature will always be the same, and will depend only on the time. In reality however, the thermal properties of the building materials will be a determining factor for the resulting temperature field in the fire event [2]. Thermal insulators will require less heat than a concrete block to reach the same temperature, which means, that these two materials will have a significantly different behaviour in a real fire. This will affect not only temperature of the construction element, but also the way how fire develops in the building.

The aim of this paper is to underline this feedback loop, which also can be observed and measured within the standardized fire testing. To present this, the authors will discuss the

\footnotetext{
*Corresponding author: w.wegrzynski@itb.pl
} 
factors influencing the energy balance within a test furnace, and compare a few different furnace fire resistance test results. A focus is put on the heat (fuel) consumption in the tests. This exercise shows, that standardized fire testing does essentially lead to completely different fire scenarios for the "same" standardized test, dependant on the material being tested.

\subsection{Early history of fire testing}

The first 100 years of the history of fire testing was thoroughly reviewed by Babrauskas and Williamson, the period between 1880 and 1918 in [3], and 1918 - 1978 in [4]. Some useful information on the historical context of fire testing are also gathered in $[5,6]$.

The goal of the first fire tests was to assess the differences in fire behaviour of popular materials of late 19th Century - wood, masonry, light bricks, terra-cotta, iron beams and concrete. Heavy masonry provided generally good protection against fire, however, it was costly for multi-storey buildings that emerged in the 1870's. Their replacement - terra-cotta arches, lighter bricks and iron beams had variable fire resistance. Observations of the real fires (mainly related to the steel columns) shown, that these solutions were not always reliable, and required additional fireproofing. In some cases, the additional protection was also unreliable, as the terra-cotta protection often felt off shortly once the fire bursted. Dangerous situations were also observed when the firefighters approached the fire with water, as the rapid cooling often led to structure collapse.

Lack of sound basis for fire protection caused an emergence of new testing procedures. Babrauskas [3] reports that the first fire tests date back to 1790's in London, however, these tests preceded the availability of equipment to measure fire temperatures. First "real" fire resistance tests were performed in the 1870's for floors and 1880's for columns. The test procedures of that time were straightforward - they involved building a mock-up furnace compartment, filling it with combustible material (wood or coal), and performing a free burn for a prolonged time (in some cases multiple hours). As high temperature measuring thermocouples and pyrometers were still not known at that time (first high-temperature pyrometer is attributed to Le Chatelier in 1890's [7]), the temperature measurements in the tests were carried through observation of melting of various alloys with a known melting point, or with Seger cones. This only gave qualitative information on what temperature was reached, not the progression of temperature in function of time. The limitations of the temperature measurement in the early tests had a surprisingly profound effect on further, 150year long history of fire testing.

In the early 1900's, the measurement of temperature through platinum wire devices was possible, Researchers reported [3] temperatures from $\sim 800^{\circ} \mathrm{C}-1100^{\circ} \mathrm{C}$ depending on the test, measurement method and type and size of the sample. This temperature range is similar to the temperatures observed today in fully developed fires. In the 1900's and 1910's furnaces were built to replace the ad-hoc testing setups used previously, and more reports on the results of fire testing were described in the literature. Besides floors and columns, more building elements underwent testing - doors, walls, glazing and theatre curtains.

\subsection{Standardisation}

Babrauskas reports [4] that first standardized methods emerged in Great Britain in 1903, and described three classes of endurance: (a) full, (b) partial and (c) temporary. These classes were related to (a) $120-240$ min endurance to $982^{\circ} \mathrm{C}$, (b) $90-120$ min endurance to $982^{\circ} \mathrm{C}$ and (c) $45-60 \mathrm{~min}$ to $816^{\circ} \mathrm{C}$. What is interesting is that this standard also had load-bearing requirements, in the form of a substitute load for floors and geometrical (thickness or area) requirements for partitions and doors. After some changes to the classes, temperature ratings 
and the standard recommendations this standard was about to be adopted by NFPA in USA (1914). However, this didn't happen and in 1916-17 strong effort was taken to prepare a U.S. fire standard. The effect of this work was the new standard ASTM C19 (later renumbered E119[8]), issued on the Feb $24^{\text {th }}, 1917$. This was the first standard that proposed the fire load in the furnace with a concept of a temperature-time curve, shown in the Fig. 1. In fact, this curve is still in use today, widely known as the "standard temperature-time curve", or "ISO 834 temperature-time curve" [9]. The origins of this curve can be tracked down to an approximation of a dozen temperature-time curves, obtained in various fire tests. Also, some of the basic ideas of fire testing, such as substitute load with weights are also in use to this day [10].

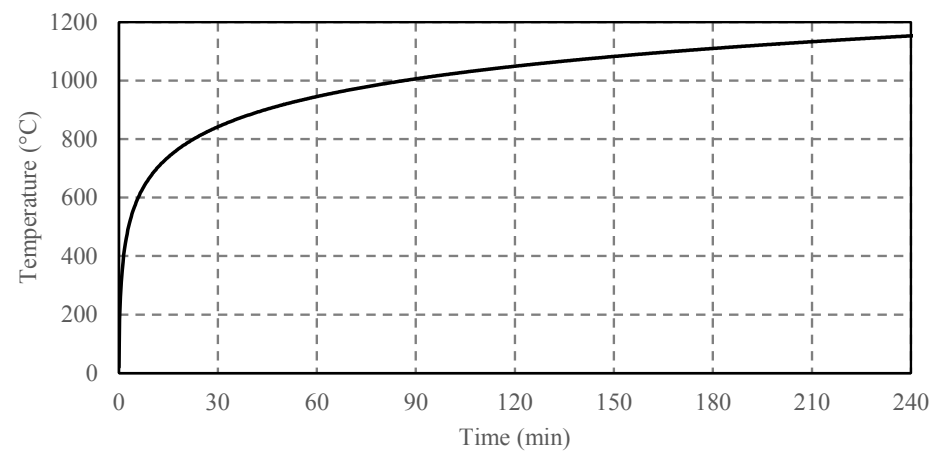

Fig. 1. Standard temperature-time curve.

Analysing the history of the fire testing, and the origins of the standard temperature-time curve, three significant problems can be brought up by modern fire science:

a) Different materials require a different amount of heat, to heat up the surrounding gas to the temperature of the standard curve, which means that different power of the fire is required in each of the tests. This means that the test standardizes the effect of the fire, and not the fire itself (and any positive effect that material may have on the fire in a compartment is generally not included in the test). Early furnaces, for which the standard temperature-time curve was created were a rather good representation of real compartments, as they used natural fuel and were not insulated, while later furnaces (insulated, gas-fuelled) were artificial constructs meant to efficiently perform the tests, and not mimic the natural fires;

b) The growth of the fire in a compartment will depend on its size, height, materials and fuels. It is not possible to average all of the fires into same growth function, as it was done for the standardized fire. Furthermore, the temperatures will be different in various spatial locations in the compartment, while the standard temperature-time curve is used universally for multiple kinds of partitions and structural elements.

c) Temperature estimations in the tests were done in majority through melting-point of alloys, or new at that time - platinum-rhodium thermocouples, which may yield a significant error in the measurements. These values were also not corrected for radiation. The $926^{\circ} \mathrm{C}$ temperature point was chosen arbitrarily based on a limited amount of experiments (furnace tests, not real compartment fires).

\section{Energy balance in a furnace}

The modern knowledge of the fire phenomena is profoundly different from that of XIX-th century. We understand that the heat and mass transfer in the compartment is what dictates the combustion process, its length and severity, while the temperature is only its 
result. For a very small compartment, it is easy to write a generalized form of energy balance equation (1), Fig. 2:

$$
\dot{q}_{c}=\dot{q}_{L}+\dot{q}_{W}+\dot{q}_{R}+\dot{q}_{B}
$$

where $\mathrm{q}_{\mathrm{c}}$ is the heat flux released by the fire, $\mathrm{q}_{\mathrm{L}}$ is the flux lost through the openings (convection), $\mathrm{q}_{\mathrm{w}}$ is the heat flux lost to the walls, $\mathrm{q}_{\mathrm{R}}$ is the heat flux lost through radiation out of the compartment and $\mathrm{q}_{\mathrm{B}}$ is the flux lost to heat the fuel.

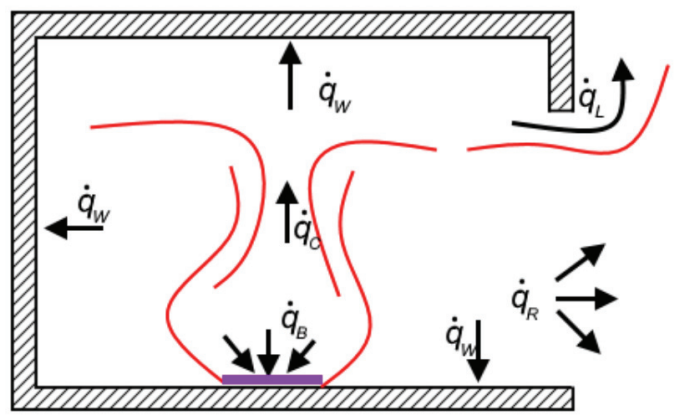

Fig. 2. Heat loses in a fire in a small compartment.

In the fire testing, the losses through the openings are only due to the ventilation of the furnace, which is used to maintain a constant pressure in the furnace. In an idealized case, the mass removed from the furnace will be equal to the mass of the products of the stoichiometric combustion in the furnace (2).

$$
\mathrm{CH}_{4}+2 \mathrm{O}_{2}+7.52 \mathrm{~N}_{2} \rightarrow \mathrm{CO}_{2}+2 \mathrm{H}_{2} \mathrm{O}+7.52 \mathrm{~N}_{2}
$$

Assuming perfect reaction kinetics, one mole (approx. $16 \mathrm{~g}$ ) of methane gas burnt in the furnace will produce $0.889 \mathrm{MJ}$ of energy, and this reaction will yield 290,56 g of products. For ease of further considerations, it may be assumed that for every $1 \mathrm{MW}$ of energy emitted in the fire, $327 \mathrm{~g}$ of products have to be removed from the furnace. One additional simplification taken here is the assumption that the mixture introduced to the furnace is in a stoichiometric ratio, while in reality, it will be fuel lean (the exact ratio is adjusted on the fly by the furnace automation system). The approximated specific heat of the mixture of the products was calculated in function of the temperature, and based on the conservation of energy, the energy required to heat the products of reaction releasing $1 \mathrm{MJ}$ of energy, from their initial temperature of $15^{\circ} \mathrm{C}$ is shown in Fig. 3. To heat up the products of reaction (2) to $1000^{\circ} \mathrm{C}$ approximately $440 \mathrm{~kJ}$ will be used. As the temperatures in the furnace are close to $850^{\circ} \mathrm{C}-1100^{\circ} \mathrm{C}$ for most of the standardized test, this means that out of every $1 \mathrm{MW}$ introduced to the furnace, 35 to $45 \%$ is inherently lost through ventilation to maintain the pressure balance in the furnace. 


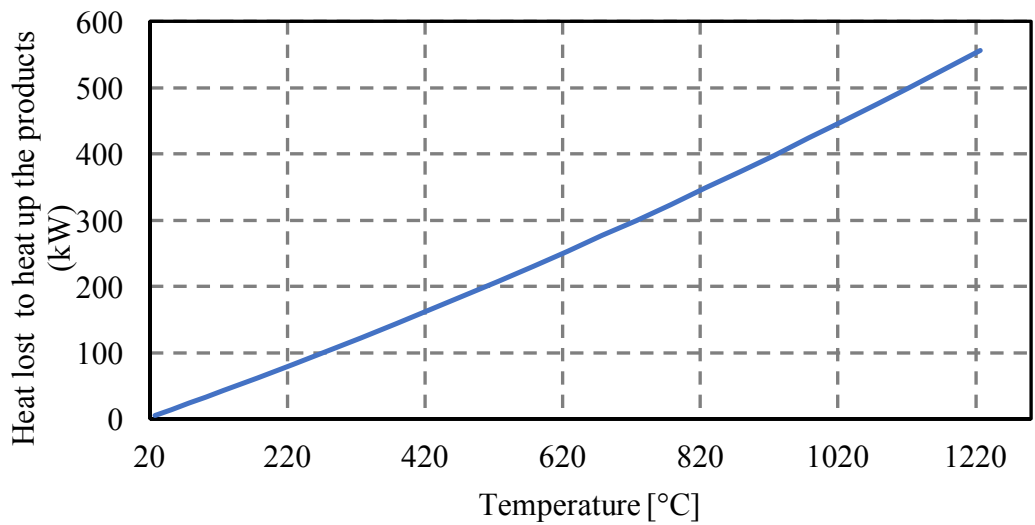

Fig. 3. Heat required to heat up the products of reaction (2), which released 1,00 MJ of energy to a given temperature (heat lost with the ventilation of the furnace at given temperature calculated with average specific heat of products in function of temperature).

The remaining 55 - $65 \%$ of the heat generated in the furnace is transferred through other ways - primarily to heat up the furnace walls, test sample and the mounting structure. For practical considerations, the losses to the furnace walls can be omitted, due to their insulation. The radiation and heat loss to the source of fire can be omitted as well, as the furnace is a closed system. The dominant factor for the heat transfer in the furnace is the heat transfer through the sample, which will be determined by the thermal properties of the material being tested. This means, that the fire tests of different materials must employ a different heat release rate, to make up for the different losses in each test. As only the temperature-time relation is conserved between the fire tests, each of them goes through a completely different fire. Yet, the rating obtained by the elements, is the same.

An additional factor to consider in solving the energy balance of the furnace, is the combustibility of the building material used in the fire test $[11,12]$. If the material can burn inside of the furnace, this will change the heat balance, as the additional source of heat will be introduced, Fig. 4 - 5. In such an event, the furnace automation will adapt to the new condition inside, by limiting fuel and increasing the ventilation rate, to maintain the prescribed temperature-time curve. This means, that if combustible material is tested inside the furnace, the system limits the fire, to maintain the prescribed temperature-time curve.

a)

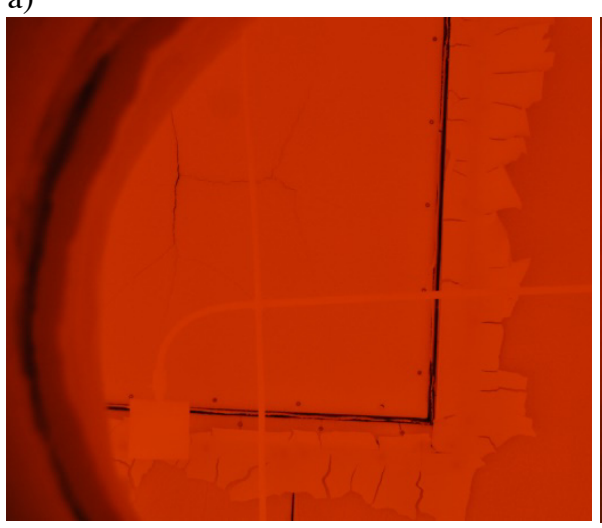

b)

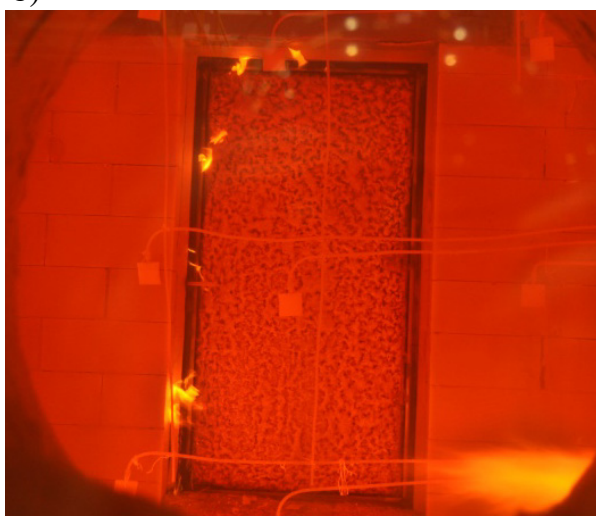

Fig. 4. View of test samples (incombustible) inside of a furnace - (a) gypsum plasterboard, (b) steel doors with interior insulation. 


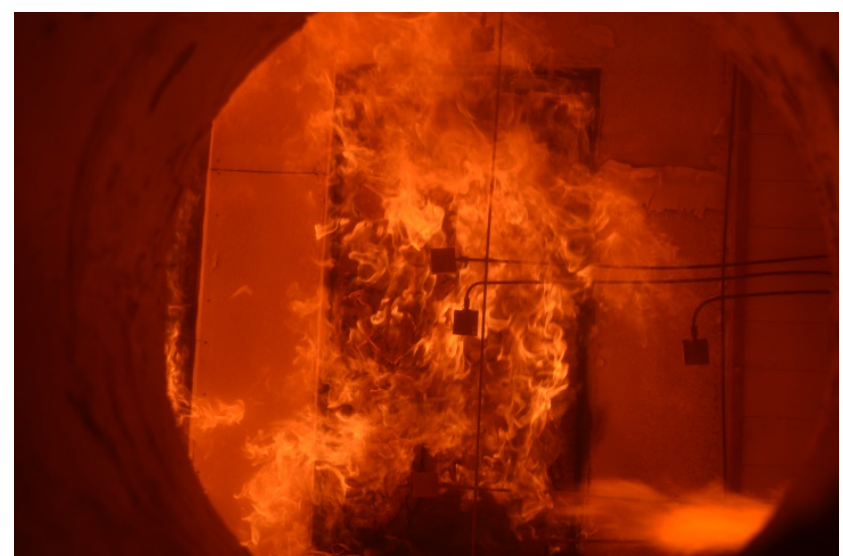

Fig. 5. View of test sample inside of a furnace - wooden doors (combustible).

\section{Comparison of chosen furnace tests}

Given the following assumptions:

a) the temperature in the furnace is defined as a function of time, $\mathrm{T}=\mathrm{f}(\mathrm{t})$;

b) the furnace automation chooses the amount of fuel introduced to the furnace to follow the temperature-time curve as closely as possible;

c) the due to furnace ventilation are a function of the temperature and the pressure inside the furnace;

the amount of heat introduced to the furnace during every test will depend mainly on the material properties of the tested sample. This means that the "fire" of the test is different for every material. Comparison of the temperature-time curves for chosen furnace tests for the standard temperature-time curve, and corresponding heat release in the furnace is shown in Fig. $6-7$. The reader must be advised, that the reading of the heat release rate in the furnace is used only as an informative feature for the furnace operator, and is recorded with a low resolution, with $\sim 0.1 \mathrm{MW}$ uncertainty.

The materials presented in this comparison are (a) gypsum plasterboard wall, (b) wooden doors $(1.8 \times 2 \mathrm{~m})$ in AAC wall, (c) glazed aluminium doors in AAC wall and (d) array of approx. 30 different penetration seals of various sizes in AAC wall. All of these materials were tested for the same temp.-time curve (ISO 834), and all of them were tested on the exact same furnace.

As shown on Fig. 6, the temperature-time was maintained by the furnace close to the ISO 834 , however, some differences are visible for sample (b) - wooden doors. This is due to the combustion of the sample within the furnace (Fig. 5). What is more interesting, is that the sample (b) required the least amount of heat from all of the presented. When the peak temperature was reached in this test, the furnace did not supply any fuel, and was actually cooling down the sample. In case of penetration seals, a large initial peak is observed, much higher than for the other materials. The largest amount of heat was consumed by the glazed door test (c), and for this experiment the heat release rate within the chamber was close to uniform during the whole duration of the experiment. Similar effect, but requiring lower amount of heat, was observed for the plasterboard wall (a). 


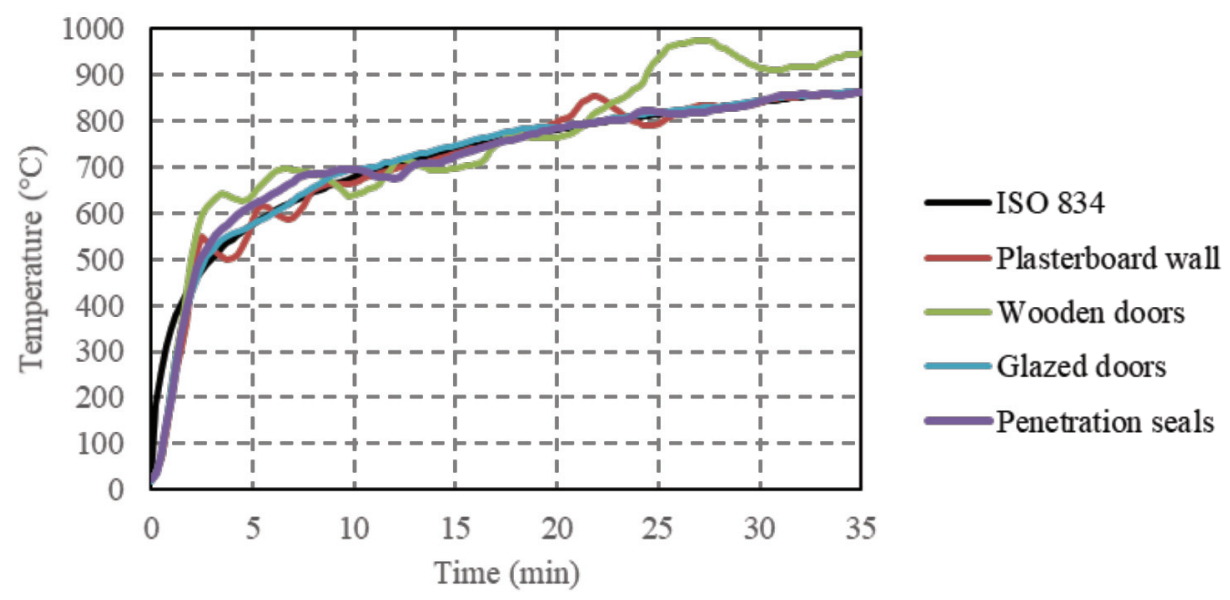

Fig. 6. Mean temperature in the furnace measured in chosen fire resistance tests of walls and doors.

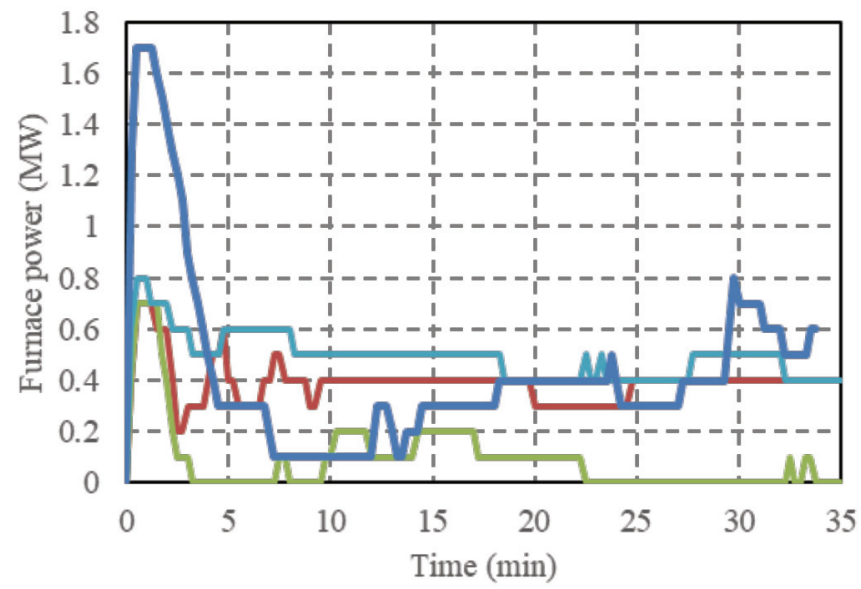

Plasterboard wall

Wooden doors

Glazed doors

Fig. 7. Heat release rate in the furnace, for the tests presented in Fig. 6.

\section{Conclusions}

The goal of standardized fire testing was to provide an uniform benchmark for various building materials, that would allow to measure their resistance to the high temperatures observed in real fires. However, due to limited testing capabilities of late XIX-th century laboratories, the only way to quantify the fire was through the temperature measurements. This led to emergence of a test, that standardized the effects of a fire, and not the fire itself. While omitted by the early fire-researchers, we know that the feedback loop between building materials and fires in real buildings is profound. This feedback loop was demonstrated in this paper through a discussion of the energy balance within a furnace, and presentation of real fire tests results for various construction materials.

The materials used in the building will change the results of the fire, and may even change its behaviour. Now they are chosen solely based on the rating index they receive, which promotes materials that either contains structural water (such as gypsum, concrete) or 
incombustible materials that have low thermal conductivity (thermal insulations like stone mineral wool). While being perfect against the standardized test, these materials may not necessarily be the best solutions for a real case scenario, as shown in literature [2]. More to that, behaviour of combustible materials, such as structural wood, is not well represented within the standard furnace tests, as their combustion during the test does significantly influence the energy balance within the furnace.

This short paper presents another proof of how the standard fire cannot be taken as a representative scenario for real fires. Yet, it is still the driving force in the research and development of new fire-protection materials and techniques. The fire science community is aware of this problem, and have voiced these issues multiple times, however, for the building industry the paradigm shift from 19th century intuition into 21 st century science has not yet occurred.

\section{References}

1. W. Węgrzyński, P. Sulik, Bull. Polish Acad. Sci. Tech. Sci. 64, 719-730 (2016)

2. D.D. Drysdale, An Introduction to Fire Dynamics, 3rd Edition (Wiley, 2011)

3. V. Babrauskas, R.B. Williamson, Fire Technol. 14, 304-316 (1978)

4. V. Babrauskas, R.B. Williamson, Fire Technol. 14, 304-316 (1978)

5. H.E. Nelson, Conference on Fire Safety Design in the 21st Century (1991)

6. I.S.F. Marshall, History of Fire and Fire Codes (Iowa Dep. Public Work, 116)

7. B.L.B. Hunt, The Early History of the Thermocouple, 23-28 (1964)

8. ASTM E119 (1917)

9. ISO 834-1 (1999)

10. G. Kimbar, P. Roszkowski, P. Sulik, AIP Conf. Proc. 1922, 80009 (2018)

11. J. Fangrat, Fire Mater. 41, 99-110 (2017)

12. J. Fangrat, Bull. Polish Acad. Sci. Tech. Sci. 64, (2016) 